\title{
Medication Reconciliation: Barriers and Facilitators from the Perspectives of Resident Physicians and Pharmacists
}

\author{
Kenneth S. Boockvar, MD, MS ${ }^{1,2,3}$, Susan L. Santos, $\mathrm{PhD}^{4,5}$, Andre Kushniruk, PhD ${ }^{6}$, Christopher Johnson, $\mathrm{PhD}^{7,8}$, \\ Jonathan R. Nebeker, MD ${ }^{9}$
}

\begin{abstract}
${ }^{1}$ Geriatrics Research, Education, and Clinical Center, James J. Peters Veterans Affairs Medical Center, Bronx, New York; ${ }^{2}$ Department of Geriatrics and Palliative Medicine, Mount Sinai School of Medicine, New York, New York; 3Jewish Home Lifecare, New York, New York; ${ }^{4}$ VA New Jersey Health Care System, East Orange, New Jersey; ${ }^{5}$ Department of Health Education and Behavioral Science, University of Medicine and Dentistry of New Jersey, New Brunswick, New Jersey; ${ }^{6}$ School of Health Information Science, University of Victoria, Victoria, British Columbia, Canada; ${ }^{7}$ Department

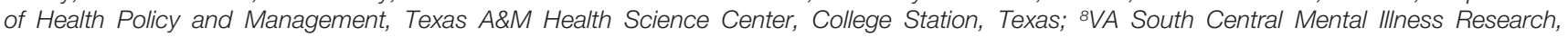
Education, and Clinical Center, and Houston Center for Quality of Care and Utilization Studies, Michael E. Debakey VA Medical Center, Houston, Texas; ' VA Geriatrics Research, Education, and Clinical Center, and University of Utah, Salt Lake City, Utah
\end{abstract}

BACKGROUND: Medication reconciliation can prevent medication errors and harm when patients transition between hospital and other care settings. Though a Joint Commission hospital Patient Safety Goal since 2006, organizations continue to have difficulty implementing the process.

OBJECTIVE: To determine factors that influence performance of medication reconciliation in a hospital setting with a computerized medication reconciliation tool.

DESIGN: Cognitive task analysis (CTA) and focus group interviews.

SETTING: Urban, academic, tertiary-care Veterans Affairs medical center.

PARTICIPANTS: Internal medicine house staff physicians (n $=23)$ and inpatient staff pharmacists $(n=12)$.

MEASUREMENTS: CTA participants verbalized their thoughts while they completed medication reconciliation with the computerized tool. Focus group participants described medication reconciliation's purpose and effectiveness, how they completed the task, and its barriers and facilitators. Interviews were recorded and analyzed using social science methods for analyzing qualitative data.

RESULTS: Participants agreed that a central goal of medication reconciliation is to prevent prescribing errors, but disagreed about whether it achieves this goal. Computerization facilitated the task, but participants said that computers and patients can be unreliable sources of information. Participants varied in how they sequenced components of the task. When time was limited, physicians considered other responsibilities higher priority. Both physicians and pharmacists expressed low self-efficacy, ie, low perceived capability to achieve the objectives of the process.

CONCLUSION: Key barriers to medication reconciliation are unreliable sources of medication information and tasks that compete for providers' time and attention that they consider higher priority. Addressing these barriers while increasing providers' self-efficacy might improve medication reconciliation and its outcomes. Journal of Hospital Medicine 2011;6:329-337. (c) 2011 Society of Hospital Medicine
Adverse drug events (ADEs) occur when patients transition between the hospital and other care settings. Medication reconciliation, a process by which a provider obtains and documents a thorough medication history with specific attention to comparing current and previous medication use, can prevent transitionrelated errors and harm in a variety of care locations. ${ }^{1-3}$ Nevertheless, poor intersite communication, ${ }^{4}$ flawed reconciliation of drug regimens, ${ }^{2}$ unreliable

*Address for correspondence and reprint requests: Kenneth $\mathrm{S}$. Boockvar, MD, MS, James J. Peters VA Medical Center, 130 West Kingsbridge Road, Bronx, NY 10468; Tel.: 718-584-9000, ext. 3807; E-mail: kenneth.boockvar@mssm.edu

Additional Supporting Information may be found in the online version of this article.

Received: July 2, 2010; Revised: November 16, 2010; Accepted: November 28, 2010

2011 Society of Hospital Medicine DOI 10.1002/jhm.891

Published online in Wiley Online Library (Wileyonlinelibrary.com). patient history-taking, and poor provider decisionmaking ${ }^{5}$ continue to contribute to transition-related ADEs.

The Joint Commission introduced medication reconciliation as a hospital National Patient Safety Goal in 2006. However, because organizations have had difficulty implementing the process, it stopped citing medication reconciliation deficiencies in its accreditation surveys. ${ }^{6}$ Although regional and national initiatives have attempted to improve implementation of medication reconciliation-using provider education, workflow, and process reorganization, and organizational change $^{7}$ - a recent field review by the Joint Commission suggests that healthcare organizations remain unable to ensure effective medication reconciliation, citing factors beyond the organizations' control, especially unreliable patient histories. ${ }^{8}$ Still, the process is slated to return as an accreditation requirement of the Joint Commission on July $1,2011 .^{8}$ 
The objective of this study was to determine factors that influenced physicians' and pharmacists' performance of medication reconciliation in a hospital setting with a computerized medical record and medication reconciliation tool, with the goal of informing an organization's approach to implementation. We conducted individual cognitive task analysis (CTA) interviews and focus group interviews to ascertain physicians' and pharmacists' opinions on the purpose and effectiveness of medication reconciliation, their approach to completing the task, and task facilitators and barriers.

\section{METHODS}

\section{Setting and Medication Reconciliation Process}

The study setting was an urban, academic, tertiarycare Veterans Affairs (VA) medical center. A computerized medication reconciliation tool and process were developed in 2005 to comply with the Joint Commission's National Patient Safety Goal. ${ }^{6}$ The tool was embedded in the VA's Computerized Patient Record System (CPRS) and consisted of a dialogue with which a provider (physician, pharmacist, or other provider) could: 1) view the patient's outpatient medication use, for the last 90 days, from VA computerized pharmacy data; 2) view current VA inpatient orders; 3) record discrepancies between patient-reported medications, and outpatient and inpatient medications in the VA computerized database; 4) record diagnostic indications for, and responses to, these discrepancies; and 5) produce a medication reconciliation document, which was a separate progress note (Figure 1). The tool did not directly facilitate ordering; however, in CPRS, outpatient orders could easily be copied to inpatient orders and vice versa.

Two versions of the medication reconciliation process were implemented upon hospital admission: one in which the physician initiated and completed a reconciliation that was then reviewed by a pharmacist (Figure 2A) - the process primarily used on the medical and surgical services; and one in which, after the physician wrote admission orders, the pharmacist initiated and completed the reconciliation and communicated his or her findings with the physician (Figure 2B) - the process primarily used on the psychiatric service. At discharge, after the physician wrote discharge orders, the pharmacist completed a reconciliation of preadmission, inpatient, and discharge orders using a tool similar to the admission one (Figure 1). The pharmacist then communicated the reconciliation findings to the physician, similar to the admission medication reconciliation process shown in Figure 2B. These processes and tools were in place for 18 months at the time of the cognitive task analysis, which took place in June 2007, and 32 months at the time of the focus groups, which took place in August 2008.

\section{Participants}

Participants consisted of internal medicine house staff physicians rotating on the inpatient service $(\mathrm{n}=23)$ and inpatient staff pharmacists $(\mathrm{n}=12)$. Overall, 14 $(40 \%)$ were female. The 23 house staff physicians represented approximately $64 \%$ of the total house staff inpatient staffing. Thirteen $(57 \%)$ were in postgraduate year 1 (PGY1), and 10 (43\%) were in PGY2 or higher. The 12 pharmacists represented approximately $50 \%$ of the total pharmacist inpatient staffing. Individual CTA interviews took place at the end of the academic year (June) with participants who were highly experienced with the process of medication reconciliation in the VA setting. Focus groups took place at the beginning of the academic year (August) with participants who had to endorse the statement that they were experienced completing medication reconciliation. Subjects participated in either the individual or focus group interviews, but not both. Physicians and pharmacists were interviewed separately. All participants provided written informed consent, and the Institutional Review Board of the James J. Peters VA Medical Center approved the study procedures.

\section{Data Collection \\ Theoretical Model}

The Integrated Change Model $^{9}$ guided our approach to data collection and analysis. It indicates that a person's motivation, intention, and ability determine whether a behavior will be carried out. A person's motivation is influenced by attitudes (eg, perceived pros and cons of the behavior), social influences, and self-efficacy (eg, perceived capability). The behavior is also influenced by environmental and physical factors-in this case circumstances of the patient encounter, information systems, and the medication reconciliation tool.

\section{Individual Interviews}

We conducted individual CTA interviews with 7 physicians and 5 pharmacists. During CTA, participants verbalized their thoughts while they completed medication reconciliation for at least 1 actual case, and at least 1 standardized (fictitious) case, using the computerized medical record and tool. The purpose of this "think aloud" exercise was to provide information on medication reconciliation tool functionality and usability, problems in human-computer interaction, and the impact of the tool on decision-making, clinical practice, and workflow. As the participants interacted with the medication reconciliation tool, computer screens, mouse clicks, and menu selections were recorded using screen recording software (Hypercam®), and the participants' "thinking aloud" was audio-recorded. This provided the experimenters with context for analyzing and coding subjects' verbalizations (ie, playback of the screens provided detail about the subjects' interaction with the tool, including 


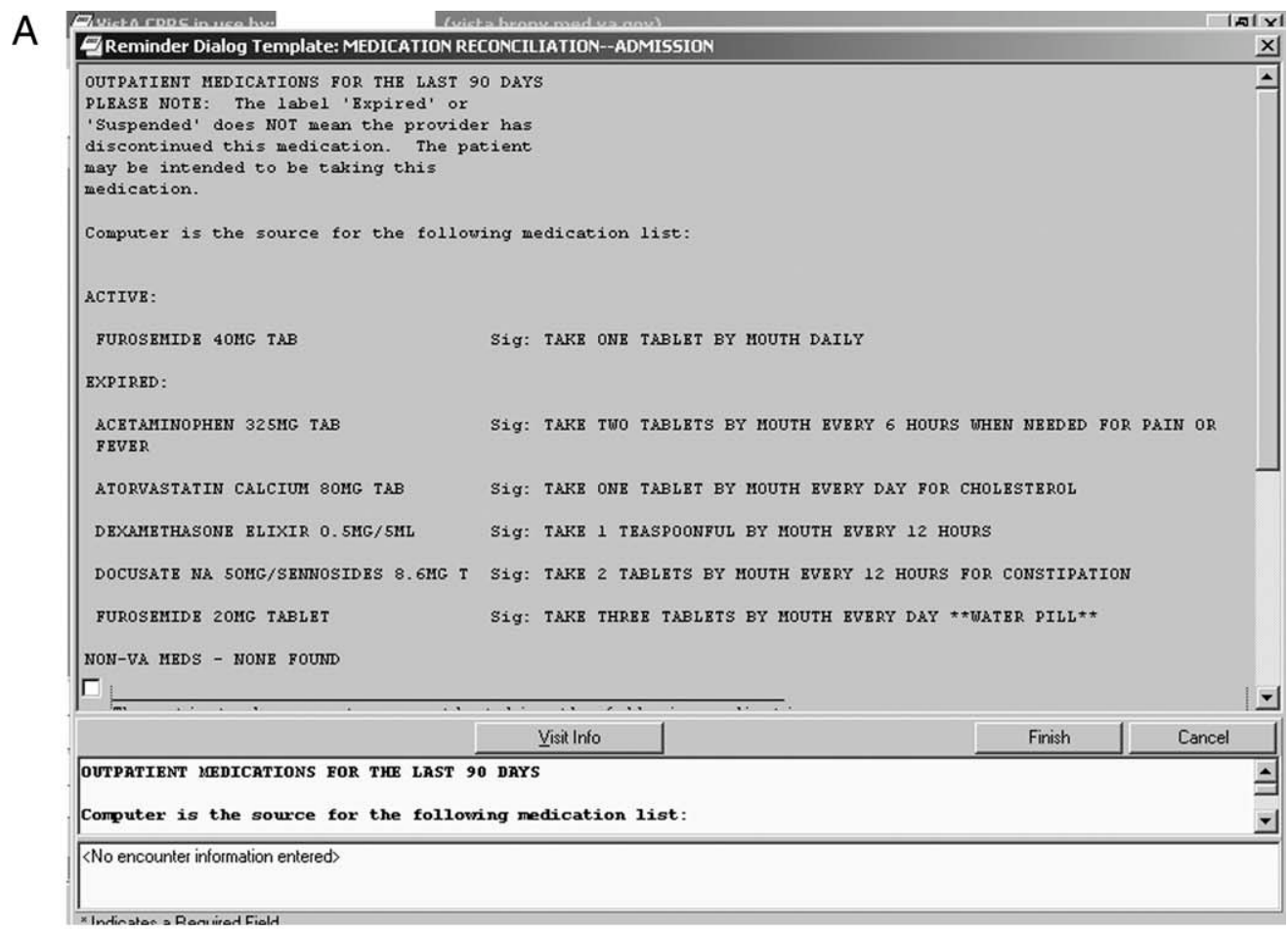

B

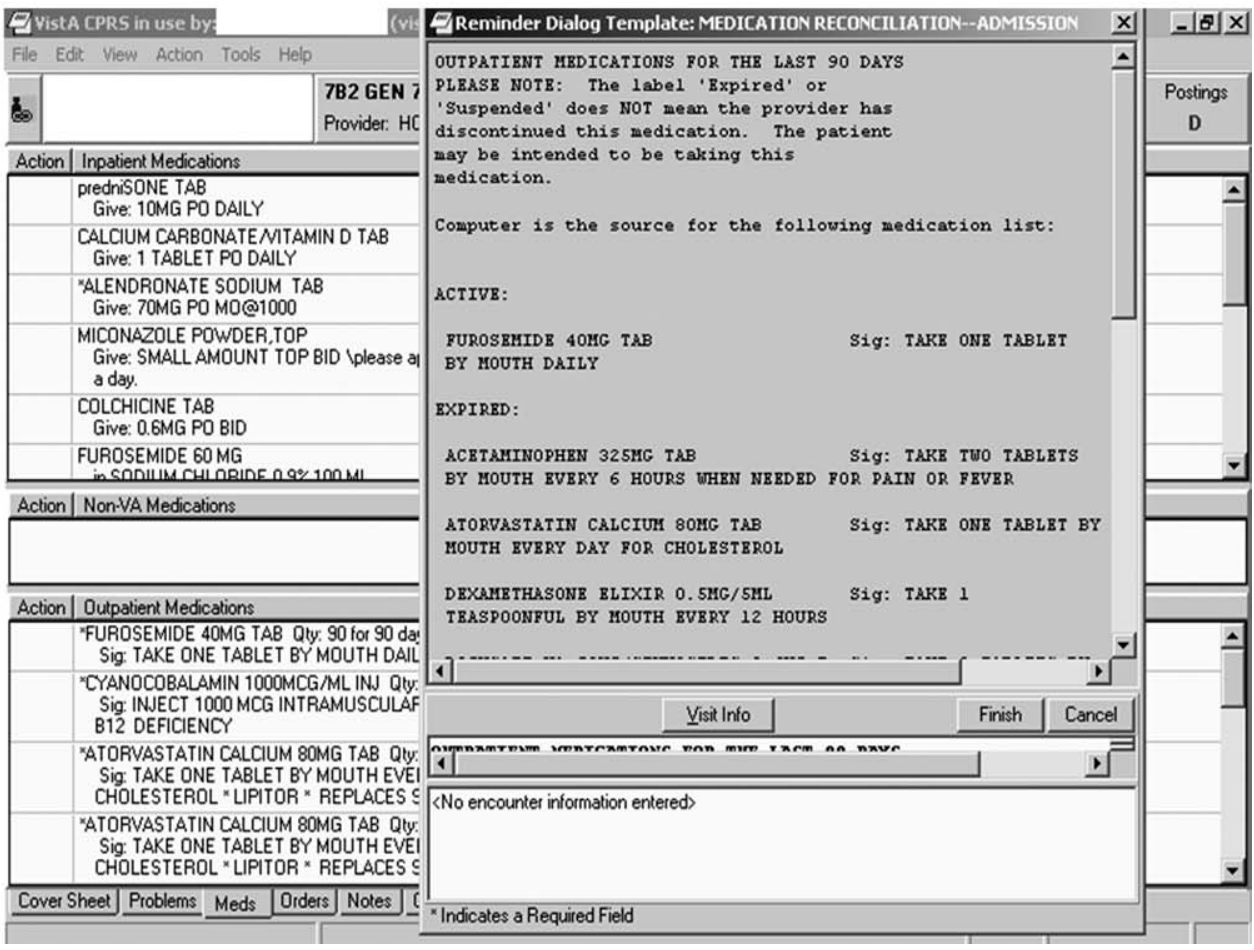

FIG. 1. Computer screen shots (A-E) of the medication reconciliation tool used at hospital admission.

what functions of the tool they accessed, and problems they may have encountered). Immediately after completing the tasks, subjects were briefly interviewed about their impressions of the tool and their interaction with it. CTA sessions took 30-50 minutes per participant. Audio- and screen-recordings were synchronized and transcribed.

\section{Focus Group Interviews}

We conducted 3 focus groups, 2 with house staff physicians ( $\mathrm{n}=9$ and $\mathrm{n}=7$ ), and 1 with pharmacists $(\mathrm{n}=7)$, for a total of 23 focus group participants. The focus group discussion guide was informed by the results of the CTA and began with broad, open-ended questions, ${ }^{10}$ followed by a series of more specific 


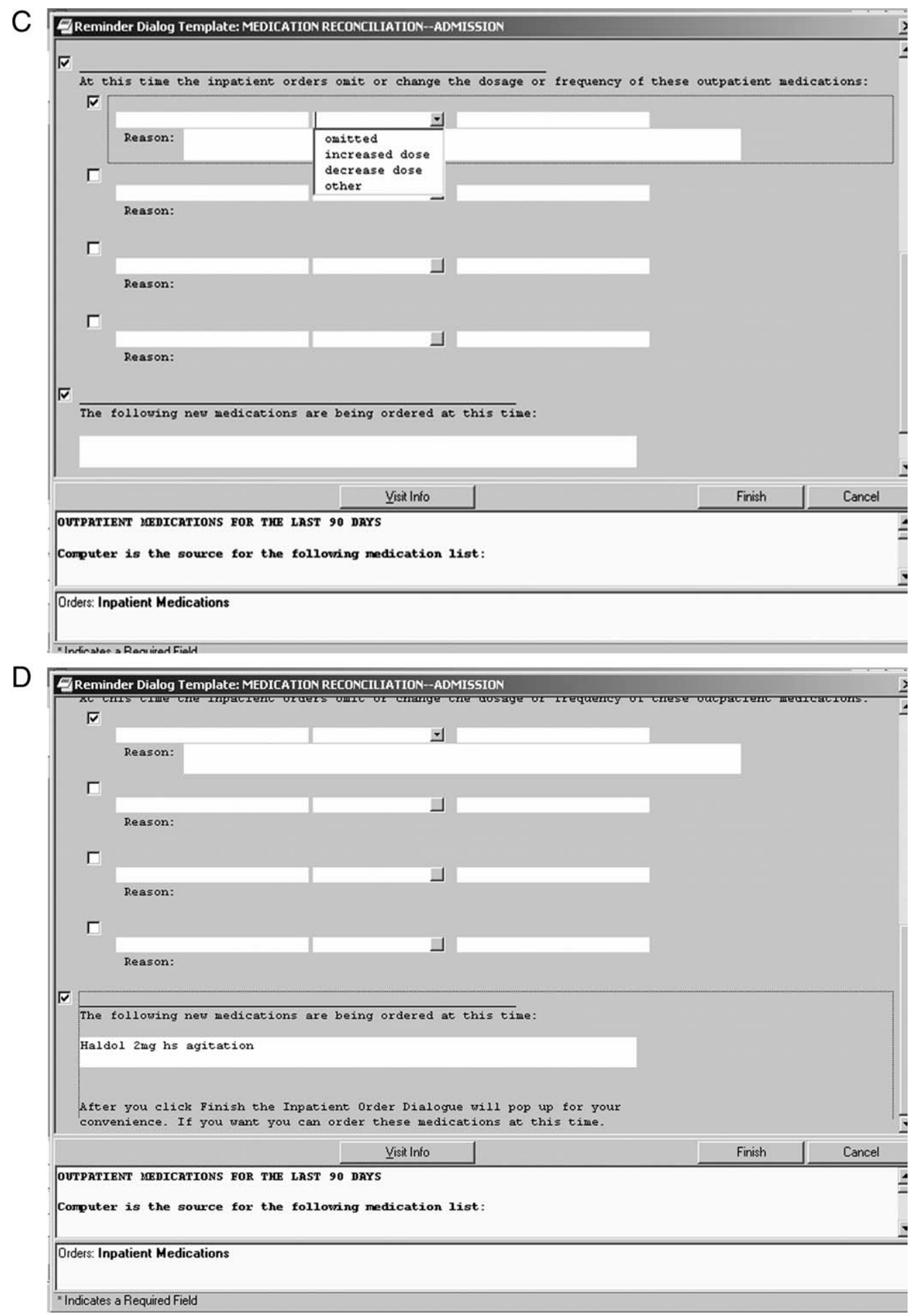

FIG. 1. (Continued)

probes. Participants were asked to describe medication reconciliation and its purpose, whether they thought that the process influenced their decision-making and was effective, and how they go about completing the process. Probes included how the task fit into daily workflow, time needed to complete the task, and its priority relative to other tasks. A set of questions asked participants to report barriers and facilitators to completing the task, training needs and experience, and their suggestions on how to improve task implementation and completion. The discussion also included participants' views of the optimal roles of physicians and pharmacists in performing medication reconciliation. Throughout, participants were encouraged to report both positive and negative perceptions. Group interviews lasted 60-90 minutes, and were 


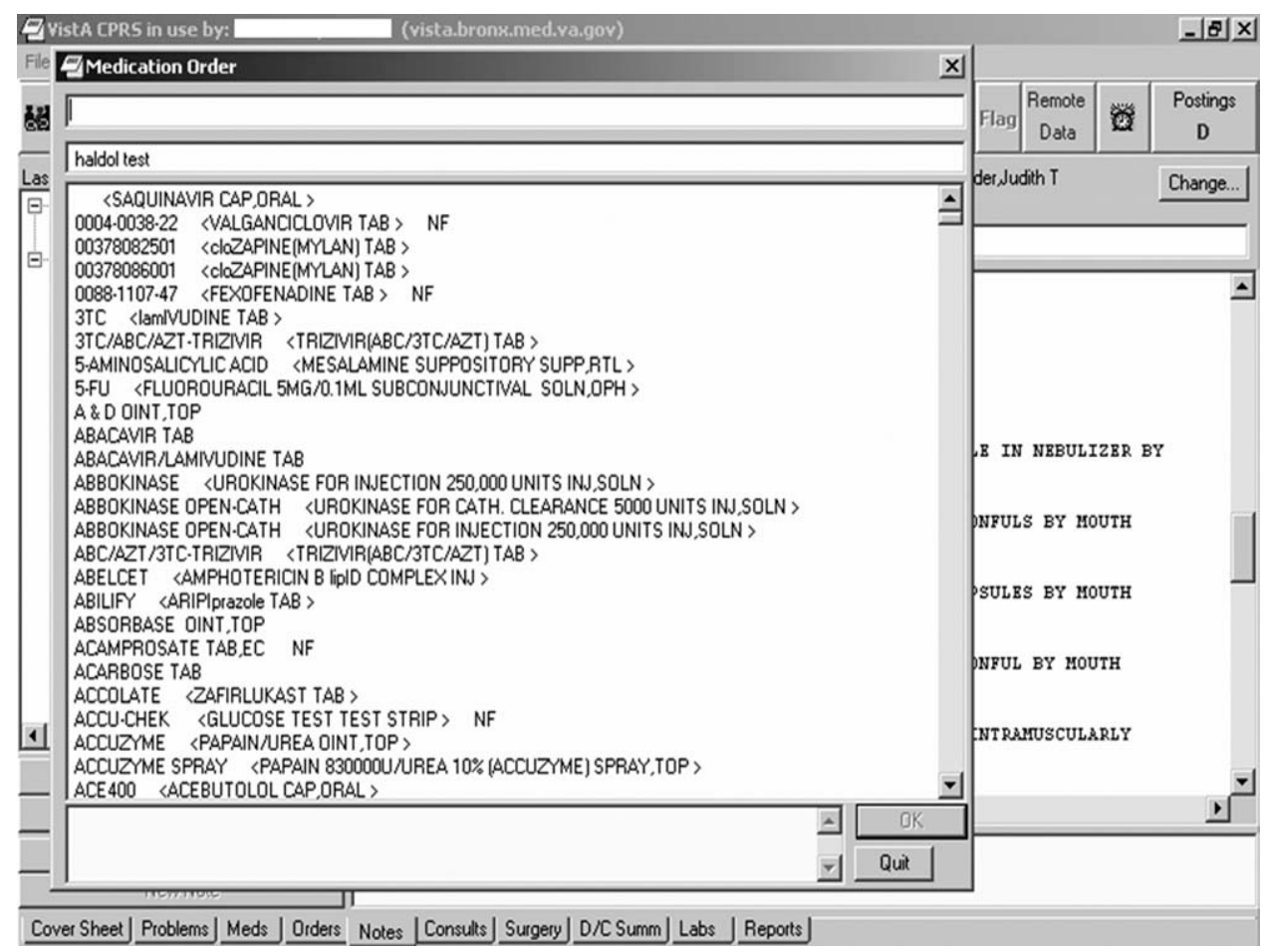

FIG. 1. (Continued)

audiotaped and transcribed. The same moderator facilitated all 3 focus groups and participated in the individual CTA interviews.

\section{Data Analysis}

CTA and focus group transcripts were analyzed using standard social science methods for analyzing qualitative data. ${ }^{11-14}$ Using multiple close readings, investigators performed initial independent coding of each of the transcripts and generated a list of concepts and domains, and a coding scheme. The coding was reviewed from the perspective of the theoretical model to determine whether additional codes were necessary. A research staff member, blinded to the study hypotheses, applied the codes to each transcript by labeling each word, phrase, or line. To test the coding scheme's reliability, a random $5 \%$ of transcript lines were coded by 2 independent coders and interrater reliability was assessed. Disagreement was reconciled by discussion and transcripts recoded as appropriate. The investigators then compared codes within and across interviews to elucidate the larger themes that emerged. Frequencies of mention of each domain were calculated. Although the original intent was to analyze the CTA and focus groups separately, themes arising from each of these 2 techniques overlapped sufficiently to allow for a combined analysis. Data were compiled to provide a description of the factors that affect medication reconciliation completion, a summary of barriers and facilitators to use of the medication reconciliation tool, and user suggestions.

\section{RESULTS}

\section{Purpose of Medication Reconciliation}

Both physicians and pharmacists agreed that a central goal of medication reconciliation is to prevent prescribing errors and adverse drug events that arise from medication utilization over time, and across place and provider. Respondents also agreed that the medication reconciliation document provides a record of patients' history of medication use and of the provider's rationale for medication changes.

Both physicians and pharmacists also indicated awareness of external necessities for completing medication reconciliation, including Joint Commission accreditation standards and, to a lesser extent, medicolegal liability concerns. On the other hand, 1 physician expressed concern that documented medication discrepancies could be interpreted as mistakes and a liability problem.

\section{Effectiveness of Medication Reconciliation}

There was overall disagreement about whether or not medication reconciliation actually achieves its goal of improving medication safety. Many physicians and pharmacists said that medication reconciliation prompts them to perform additional checking of medication lists, dosing, conditions, and interactions, and to better document medication histories and provider decision-making. On the other hand, some physicians and pharmacists saw it as mainly an administrative task and doubted whether it had any impact on patient care, as this physician indicated: "It just seems like another form to fill out ....You could be writing 


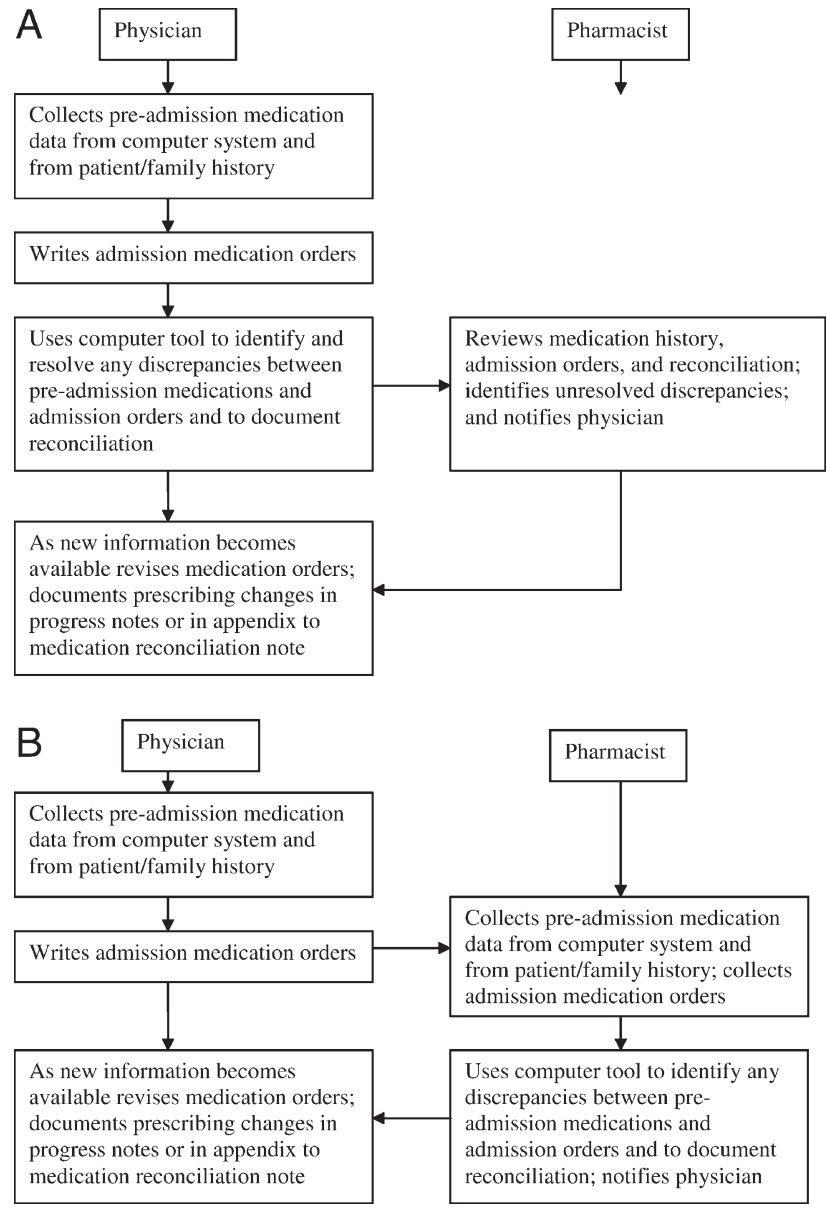

FIG. 2. (A) Flow diagram of physician-initiated admission medication reconciliation. (B) Flow diagram of pharmacist-initiated admission medication reconciliation.

a bunch of ... whatever and no one would notice and no one would say anything and it would never matter." Likewise, a majority of physicians indicated that other parts of the medical record are better sources of prescribing information than the medication reconciliation document.

\section{Medication Reconciliation Process}

Physicians and pharmacists agreed that the key components of medication reconciliation are obtaining a medication history from patients and other available sources, identifying differences among medication histories and medications being given, documenting these discrepancies and their reasons, recording a prescribing plan, and counseling the patient. Respondents indicated that the process varies depending on patient complexity, number of medications, encounter type, and provider. For example, physicians were more likely than pharmacists to complete medication reconciliation at once on admission, rather than begin the task and complete it later, as this physician indicated:

It might seem a little tough, but if you don't do it right at that moment, chances [are high] of you forgetting to do it .... So it's best done at the moment when you speak to the patient unless you're waiting for some more information.

On the other hand, this physician routinely put off completing medication reconciliation until the day after admission in order to incorporate a more developed prescribing plan:

You can't do it till the end. Until you have your whole plan.... when I do an admission note, I write down every single problem and I account for every single medication that I'm going to put someone on in the hospital or not put someone on. And I actually do the medication reconciliation the next day very easily, because I know exactly what I discontinued or why, or added and why.... I don't think it's necessary to do it that night ... [and] you think about it a little bit more.

These quotes suggests that there is an adherence benefit to completing medication reconciliation on admission as a routine, but that this may not be possible, or even desirable, when more time is needed to obtain and verify medication information and make informed prescribing decisions.

\section{Impact of the Computer on the Medication Recon- ciliation Process}

A majority of respondents cautioned about the impact of computerized information and an electronic tool on medication reconciliation. As indicated in these quotes, the first by a physician and the second by a pharmacist, providers' reliance on the computer can lead to less thorough patient interviews, and computerized medication information may be incomplete, both unintended consequences of the electronic health record:

\footnotetext{
At the VA, you can just easily import [all the information] and you don't even have to ask the patient. So I would imagine more errors get made because people just import whatever meds are in the computer.
}

If I didn't have [the computerized record], I would be doing patient interviews much more and finding out what they're taking. On the computer, you do all these beautiful notes...so I rely a lot on the computer and the whole patient contact thing kind of slides away. When you go to other hospitals, medication reconciliation is extensively patient interview, family interview, calling neighborhood pharmacies, you know, more like detective work and talking to people versus just sitting here typing, so.... But the computer is great.

\section{Who Should Perform Medication Reconciliation}

Pharmacists and physicians had mixed responses when asked who should perform medication reconciliation. Several physicians indicated that medication reconciliation duplicates what they already do on admission and in progress notes, and therefore is not a good use of their time.

Respondents from both professions questioned the quality of physicians' medication reconciliation. As 1 pharmacist stated about physicians:

They're busy. Whether you like it or not, they're busy. To compare everything, to go across all the sources whether it's what they get here, asking the patient [viewing data from other 
TABLE 1. Barriers to High-Quality Medication Reconciliation, in Order of Strength of Endorsement

\begin{tabular}{|c|c|c|c|}
\hline Barrier & Barrier Type/Level & Primary Endorser(s) & $\begin{array}{l}\text { No. of Endorsers } \\
\text { (MDs/PharmDs) }\end{array}$ \\
\hline Competing clinical tasks have higher priority & Provider & Physician & 9/2 \\
\hline Patients provide unreliable information & Patient & Physician & $6 / 1$ \\
\hline Status (active/expired/discontinued) of medications is unclear & System & Physician/pharmacist & $2 / 5$ \\
\hline Need to complete many medication reconciliations & Provider & Pharmacist & $0 / 6$ \\
\hline $\begin{array}{l}\text { Preadmission medication list generated by the tool may show medications } \\
\text { in duplicate and may require extensive scrolling }\end{array}$ & Tool & Physician/pharmacist & $4 / 2$ \\
\hline Medication reconciliation tool only picks up information on medications supplied by the VA & Tool & Pharmacist & $0 / 5$ \\
\hline Process to import non-local VA medications is slow or does not work & System & Physician/pharmacist & $3 / 2$ \\
\hline Patient's health status changes over time & Patient & Physician/pharmacist & $3 / 1$ \\
\hline $\begin{array}{l}\text { It is difficult to determine physicians' rationale for prescribing changes, } \\
\text { which is needed for the reconciliation document }\end{array}$ & Provider & Pharmacist & $0 / 4$ \\
\hline $\begin{array}{l}\text { Tool is unclear on where to insert revisions to the medication history, } \\
\text { changes to the outpatient or inpatient orders, and unresolved medication discrepancies }\end{array}$ & Tool & Physician & $3 / 0$ \\
\hline
\end{tabular}

Abbreviation: MDs/PharmDs, physicians/pharmacists; VA, Veterans Affairs medical center.

facilities]....There's nothing wrong with the computer [being] able to copy everything that's active and dropping it in. But. . .you have to look it over. That's the problem. They don't look it over.

Thus, there was a tension among a majority of respondents between a belief that pharmacists do a better job at medication history-taking and reconciliation, and a belief that physicians make the prescribing decisions and should be responsible for them. The quote also suggests that a barrier to self-efficacy among pharmacists is their dependence on physicians to write the orders needed to address the findings of medication reconciliation. Although many respondents recognized that the task needs to be a component of both profession's jobs, suggestions for collaboration between physicians and pharmacists were limited in vision. Suggestions included pharmacists' checking physicians' work, physicians cosigning pharmacists' work, or some other sequenced completion of the task.

\section{Barriers to Medication Reconciliation}

Barriers to efficient and effective completion of medication reconciliation according to respondents are shown in Table 1. Physicians and pharmacists both indicated that patients can be unreliable sources of medication information. A few respondents indicated that whereas patients' health conditions change, medication reconciliation occurs at 1 point in time; this can limit its usefulness or make it immediately obsolete.

Both physicians and pharmacists said that medication reconciliation competed for their time with other responsibilities, and physicians placed acute care responsibilities as a higher priority: "One sick patient takes all your time...so your mind is on the patient, not on the reconciliation; that's the last thing you worry about."

Pharmacists emphasized that the volume of patients is a barrier: "Give me time and I can do a perfect med rec....Honestly, it's work load....I'm sorry, that day where I had 17 people being discharged, I don't think I did such a great job on their med recs."

Respondents indicated several ways in which the computer system itself was a barrier to effective medication reconciliation. First, as previously noted, the computer only picks up information on medications supplied by the VA, and the medication reconciliation tool may only pick up medications supplied by the local facility. Second, sometimes the computer is unclear on the status of medications, as when outpatient medications are automatically discontinued after hospital admission, or when the system automatically imports a medication that is shown to be active but was only meant to be given for a short period of time, such as an antibiotic. Several barriers specific to tool usability are also shown in Table 1.

\section{Suggestions for Improving Medication Reconciliation}

Physicians' and pharmacists' suggestions for improving medication reconciliation are shown in Table 2. First, there was recognition of the need for someone in addition to the author to check the medication reconciliation document to find mistakes. Second, respondents indicated that better provider training might improve medication reconciliation's effectiveness. Both physicians and pharmacists indicated that their education consisted of a limited amount of on-the-job training, such as a "walk through" with a supervisor the first time. When asked for suggestions for improving education, both physicians and pharmacists suggested that physicians should receive case-based education, during which the purpose of the task is emphasized. These respondents, the first a pharmacist and the second a physician, called for provider feedback to improve and maintain reliability:

Have somebody really look at the quality of the reconciliation and speak to whoever did it, whether it's done correctly or not 
TABLE 2. Suggestions for Improving Medication Reconciliation, in Order of Strength of Endorsement

\begin{tabular}{|c|c|c|c|}
\hline Suggestion & Targeted Level & Primary Endorser(s) & $\begin{array}{l}\text { No. of Endorsers } \\
\text { (MDs/PharmDs) }\end{array}$ \\
\hline Place checkbox next to each medication & Tool & Physician/pharmacist & $6 / 2$ \\
\hline Order or label medication by condition or diagnosis & Tool & Physician/pharmacist & 2/3 \\
\hline $\begin{array}{l}\text { Someone in addition to the author should check the medication reconciliation } \\
\text { note and provide feedback and corrections }\end{array}$ & Provider & Physician/pharmacist & $2 / 2$ \\
\hline Enable searchable medication history & System & Physician & 2/2 \\
\hline Enable automatic importing of medication information from other VAs & System/tool & Physician/pharmacist & $1 / 2$ \\
\hline Reconciliation document should be signed by both physician and pharmacist & Provider & Pharmacist & $0 / 2$ \\
\hline Task should have dedicated staffing & Provider & Pharmacist & $0 / 2$ \\
\hline $\begin{array}{l}\text { Facilitate viewing of preadmission medication list and inpatient } \\
\text { orders side-by-side, instead of top-bottom }\end{array}$ & Tool & Pharmacist & $0 / 2$ \\
\hline Make template more concise & Tool & Pharmacist & $0 / 2$ \\
\hline Automatically convert medication reconciliation planned actions into orders & System/tool & Pharmacist & $0 / 2$ \\
\hline Automatically insert medication reconciliation documentation into admission note & System/tool & Physician & $2 / 0$ \\
\hline
\end{tabular}

Abbreviation: MDs/PharmDs, physicians/pharmacists; VAs, Veterans Affairs medical centers.

correctly. Because I've seen too many people just use the template, click, click, and then sign. You can finish the note [in] two minutes, but it's not going to be accurate and it's not going to do the patient any good.

We just keep on doing the same thing without ever learning [whether it is] the right way. That's where [we get] this [idea that] we are just doing it for the sake of doing it.

These quotes suggest that a lack of review and feedback about the reconciliation process appears to impact both perceived importance and quality.

\section{DISCUSSION}

In this study of hospital physicians' and pharmacists' perspectives on medication reconciliation, we found that although respondents agreed about its main purpose- to improve prescribing safety-a near majority believed that it was of uncertain benefit to patients and limited use to providers. This might, in part, be because of a tool that was not adequately integrated into workflow, making it extraneous to patient care. As a consequence, many respondents' indicated that when they had competing tasks, especially other acute care responsibilities, medication reconciliation was displaced in priority. Respondents indicated that unreliability of patient medication histories was also a major barrier, which is consistent with a recent Joint Commission field review in which organizations cited this as a task hindrance beyond their control. ${ }^{8}$ Lastly, respondents revealed limited perception of it being a team-oriented task.

Our study also probed providers' perceptions of the effect of computerization on completing medication reconciliation. Although study respondents indicated that the computerized tool reduced the time required to complete the task, they also expressed concern that because medication reconciliation was automated in part at the VA, they spent less time with patients on the process. This finding is important because, accord- ing to 1 study, many medications are not captured by the VA's Computerized Patient Record System, ${ }^{15}$ and a patient's lack of medication adherence may not be evident in the CPRS. This finding is also consistent with our prior work that has not demonstrated an inherent advantage to electronic communication of medication information over paper. ${ }^{16}$

Our study suggests that, for medication reconciliation to be improved, provider self-efficacy and engagement with the process must be increased. This might involve addressing negative provider attitudes, changing workflow, and improving provider confidence by improving information reliability. With regard to changing attitudes, team members should be briefed on research evidence that shows that medication reconciliation is effective in preventing $\mathrm{ADEs}^{1-3}$ and is cost-effective $^{17}$ to help to increase the value that providers place on medication reconciliation. With regard to workflow, the tool has to be optimized to facilitate information gathering, processing, and medication ordering. Our findings also suggest that medication reconciliation would benefit from widening the time window in which it should be completed (eg, to the first or second business day after admission), since this increases the time available to access multiple data sources, and for providers to update the preadmission medication history and to act on new medication information. Finally, regional electronic health information exchange would improve information reliability and provider confidence in the information.

Our findings also suggest that assignment of productive teams-consisting of physicians, physician-extenders, nurses, pharmacists, and/or administrative support staff-rather than individuals to the task might improve task completion. Efficacy and perceived capability might be improved by dividing the task into parts more easily manageable by individual team members. One example would be to assign 1 team member to record all of the sources of medication 
information available for each patient (the patient's home, pharmacies, doctors, hospitals, etc), and assign 1 or more other team members to access these sources as needed. Another example would be to assign the pharmacist to take and document the preadmission medication history (if not for all patients, then perhaps for the highest-risk patients), and assign the physician to verify the history, specify the planned action on admission for each medication, and complete the admission orders. These suggestions are consistent with a study that suggested that physician engagement and an effective team are strongly correlated with successful implementation of medication reconciliation. ${ }^{7}$

A strength of our study was its use of multiple methods (focus groups and cognitive task analysis) to collect data from key users individually while they interfaced with the system and in groups. Nevertheless, a limitation of the study is that it took place in a single hospital. Though it had a limited number of physician and pharmacist participants, the study sample represented a large fraction of the inpatient staff in those disciplines. We also did not include nurses, hospitalist attending physicians, or other disciplines that might be involved in medication reconciliation in other facilities or settings. However, our study explored the relationship between two disciplines (physicians and pharmacists), yielding findings that could apply to optimizing the function of other interdisciplinary teams.

Our findings can be used to inform improvement efforts in hospitals that have struggled to implement medication reconciliation. Given that the process is slated to return as an accreditation requirement of the Joint Commission, ${ }^{8}$ hospitals will need to find ways to strengthen the process. Our findings suggest that increasing providers' perceived capability, and confidence in the process and its outcomes, would improve their engagement in the process. This could be accomplished by improved information gathering, including better computer information systems and regional electronic health information exchange, a flexible timeframe for the process, provider training and feedback, and teamwork. In addition, hospitals can make sure their process is working by ascertaining a "gold standard" medication history on a subset of patients, and comparing the gold standard to the team's history, and admission and discharge orders. Because it is a central component of safe medication prescribing, medication reconciliation will continue to be a focus of state, ${ }^{18}$ national, ${ }^{19}$ and international safety efforts ${ }^{20}$ in the near future.

\section{Acknowledgements}

The authors are grateful for the technical assistance of Daniel Signor in the conduct of this work.

Disclosure: This work was supported by VA Health Services Research and Development Service. Dr. Boockvar is also supported by the Greenwall Foundation. The authors have no conflicts of interest to disclose.

\section{References}

1. Schnipper JL, Hamann C, Ndumele CD, et al. Effect of an electronic medication reconciliation application and process redesign on potential adverse drug events: a cluster-randomized trial. Arch Intern Med. 2009;169:771-780.

2. Pronovost P, Weast B, Schwarz M, et al. Medication reconciliation: a practical tool to reduce the risk of medication errors. J Crit Care. 2003;18:201-205.

3. Boockvar KS, Carlson LaCorte H, Giambanco V, Fridman B, Siu A. Medication reconciliation for reducing drug-discrepancy adverse events. Am J Geriatr Pharmacother. 2006;4:236-243.

4. Jones JS, Dwyer PR, White LJ, Firman R. Patient transfer from nursing home to emergency department: outcomes and policy implications. Acad Emerg Med. 1997;4:908-915.

5. Leape LL, Bates DW, Cullen DJ, et al. Systems analysis of adverse drug events. ADE Prevention Study Group. JAMA. 1995;274:35-43.

6. Joint Commission Hospital National Patient Safety Goal \#8. Available at: http://www.jointcommission.org/AccreditationPrograms/ Hospitals/NPSG/. Accessed November 10, 2010.

7. Rogers G, Alper E, Brunelle D, et al. Reconciling medications at admission: safe practice recommendations and implementation strategies. It Comm I Oual Patient Saf. 2006;32:37-50.

8. Update: medication reconciliation. National Patient Safety Goal field review results. Joint Commission online June 2, 2010. Available at: http://www.jointcommission.org/NR/rdonlyres/17295FE3-664348E6-89A5-C629 609E3F36/0/jconlineJune210.pdf. Accessed November 10, 2010.

9. Vries H, Mesters I, van de Steeg H, Honing C. The general public's information needs and perceptions regarding hereditary cancer: an application of the integrated change model. Patient Educ Couns. 2005;56:154-165.

10. Krueger R, King J. Involving Community Members in Focus Groups. Thousand Oaks, CA: Sage; 1998.

11. Miles M, Huberman M. Qualitative Data Analysis. Thousand Oaks, CA: Sage; 1994.

12. Patton MQ. How to Use Qualitative Methods in Evaluation. Newbury Park, CA: Sage; 1987.

13. Miller DC. Handbook of Research Design and Social Measurement, 5th ed. Newbury Park, CA: Sage; 1991.

14. Flick U. An Introduction to Qualitative Research. London: Sage; 1998

15. Kaboli PJ, McClimon BJ, Hoth AB, Barnett MJ. Assessing the accuracy of computerized medication histories. Am J Manag Care. 2004; $10: 872-877$.

16. Boockvar KS, Livote E, Goldstein N, et al. Electronic health records and adverse drug events after patient transfer. Oual Saf Health Care. 2010;19:1-5

17. Karnon J, Campbell F, Czoski-Murray C. Model-based cost-effectiveness analysis of interventions aimed at preventing medication error at hospital admission (medicines reconciliation). I Eval Clin Pract. 2009;15:299-306.

18. Massachusetts Hospital Association. Reconciling medications. A Medication Safety Collaborative sponsored by the MA Coalition for the Prevention of Medical Errors. Available at: http://www.macoalition.org/Initiatives/RecMeds/ProjectBackground.pdf. Accessed November 10, 2010.

19. Patient safety medication systems tools. Available at: http://www. ihi.org/IHI/Topics/PatientSafety/MedicationSystems/Tools/. Accessed November 10, 2010.

20. Danish Society for Patient Safety: Operation Life Denmark. Available at: http://patientsikkerhed.dk/en/about_the_danish_society_for_patient_ safety/activities/. Accessed November 10, 2010. 